\title{
Psychiatry in Former Socialist Countries: Implications for North Korean Psychiatry
}

\author{
Young Su Park ${ }^{1}$, Sang Min Park ${ }^{2,3}$, Jin Yong Jun ${ }^{4}$, and Seog Ju Kim², $₫$ \\ ${ }^{1}$ Department of Anthropology, Stanford University, Stanford, CA, USA \\ ${ }^{2}$ Center for Medicine and Korean Reunification, Seoul National University College of Medicine, Seoul, Republic of Korea \\ ${ }^{3}$ Department of Family Medicine, Seoul National University Hospital, Seoul National University College of Medicine, Seoul, Republic of Korea \\ ${ }^{4}$ Department of Psychiatry, Settlement Support Center for North Korean Refugee, Ministry of Unification, Anseong, Republic of Korea \\ ${ }^{5}$ Department of Psychiatry, Seoul National University Hospital, Seoul, Republic of Korea
}

\begin{abstract}
Very little information is available regarding psychiatry in North Korea, which is based on the legacy of Soviet psychiatry. This paper reviews the characteristics of psychiatry in former socialist countries and discusses its implications for North Korean psychiatry. Under socialism, psychiatric disorders were attributed primarily to neurophysiologic or neurobiological origins. Psychosocial or psychodynamic etiology was denied or distorted in line with the political ideology of the Communist Party. Psychiatry was primarily concerned with psychotic disorders, and this diagnostic category was sometimes applied based on political considerations. Neurotic disorders were ignored by psychiatry or were regarded as the remnants of capitalism. Several neurotic disorders characterized by high levels of somatization were considered to be neurological or physical in nature. The majority of "mental patients" were institutionalized for a long periods in large-scale psychiatric hospitals. Treatment of psychiatric disorders depended largely on a few outdated biological therapies. In former socialist countries, psychodynamic psychotherapy was not common, and psychiatric patients were likely to experience social stigma. According to North Korean doctors living in South Korea, North Korean psychiatry is heavily influenced by the aforementioned traditions of psychiatry. During the post-socialist transition, the suicide rate in many of these countries dramatically increased. Given such mental health crises in post-socialist transitional societies, the field of psychiatry may face major challenges in a future unified Korea.
\end{abstract}

Psychiatry Investig 2014;11(4):363-370

Key Words Psychiatry, Socialism, North Korea.

\section{INTRODUCTION}

Although North Korean refugees in South Korea reportedly have various psychiatric problems, ${ }^{1-3}$ the current state of psychiatry in North Korea is largely unknown due to limited information. This paucity of information seems inevitable because of the closed social system of North Korea. As North Korean psychiatry is based on the legacy of Soviet psychiatry, a careful review of the existing literature on psychiatry in former socialist countries may contribute to discussions of the

Received: July 12, 2013 Revised: September 16, 2013

Accepted: October 8, 2013 Available online: October 20, 2014

$\triangle$ Correspondence: Seog Ju Kim, MD, PhD

Center for Medicine and Korean Reunification, Department of Psychiatry, Seoul National University Hospital, Seoul National University College of Medicine, 101 Daehak-ro, Jongno-gu, Seoul 110-799, Republic of Korea Tel: +82-2-740-8418, Fax: +82-2-744-7241, E-mail: psychical@hanmail.net

(a) This is an Open Access article distributed under the terms of the Creative Commons Attribution Non-Commercial License (http://creativecommons.org/licenses/bync/3.0) which permits unrestricted non-commercial use, distribution, and reproduction in any medium, provided the original work is properly cited. current status and the future direction of North Korean psychiatry.

This study examined the psychiatric literature in former socialist countries by searching the PubMed, SocINDEX, and Anthrosource databases using a combination of keywords: "Socialist/Communist/Soviet" and "Psychiatry." Irrelevant articles, such as those involving psychiatry under National Socialism in Nazi Germany, were excluded. In terms of Boolean operators, articles with keywords on (socialist OR communist OR soviet) AND (psychiatry) NOT (Nazi OR National Socialism) were retrieved for review. We also refer to our previous report on in-depth interviews of North Korean defectors who had worked as physicians in North Korea. ${ }^{4}$

\section{ETIOLOGY OF PSYCHIATRIC DISORDERS}

\section{Psychosocial etiology}

Before the Russian revolution, Russian psychiatry did not 
ignore psychosocial factors as plausible causes of psychiatric disorders. Social conditions potentially linked to psychiatric disorders, such as poverty, government policies, and education, were investigated. ${ }^{5}$ However, after studies reported that long-term labor in a poor environment could cause neuroses, the Central Committee of the Communist Party of the Union of Soviet Socialist Republics (USSR) banned psychological tests related to education and industry and discouraged social explanations of the etiology of psychiatric disorders. ${ }^{6}$

Despite this general eschewal of the psychosocial etiology of psychiatric disorders, some conditions were sometimes regarded as by-products of capitalistic or reactionary thinking in the context of the political abuses of the Soviet mental health system. ${ }^{7}$ However, Western-type psychosocial approaches began in some socialist countries, such as East Germany, only after the de-Stalinization movement. ${ }^{8}$

\section{Psychodynamic etiology}

Before the Stalin era, Freudian theory was translated into Russian and psychoanalysis was accepted by Russian psychiatrists. ${ }^{9}$ The ideas of Jung or Adler were also introduced before 1930's to USSR. ${ }^{10}$ However, the Stalin government officially opposed the existence of the unconscious and proclaimed that society can control all aspects of human beings via conscious processes. ${ }^{5}$ The collective nature of socialist societies could not allow the presence of the unconscious, which was composed of irrational and selfish desires. Freudian theory was also criticized for its sexual orientation, lack of scientific materialism, and alienation from the life of workers. ${ }^{5,9}$ Stalin chose Pavlov's theory of conditioned reflexes as the basis of Soviet psychiatry. ${ }^{6}$ Although a few psychiatrists tried to combine psychoanalytic theory with Marxism, Freudian concepts were prohibited and Freudian books were virtually eliminated during the Stalin era. ${ }^{11}$ Similarly, the works of Jung, Adler or neo-Freudian school became almost inaccessible in USSR. ${ }^{11}$ It was only after Stalin's death that contemporary psychodynamic theories of Klein, Sullivan, Erikson and Lacan could be introduced into socialist countries. ${ }^{10}$

\section{Biological etiology}

Consistent with a materialist approach, Soviet psychiatrists adopted a unilaterally biological approach to psychiatric disorders. ${ }^{6}$ Kraepelin introduced the tradition of biological psychiatry in Russia. ${ }^{5}$ In 1950, the joint session of the USSR Academy of Sciences and the USSR Academy of Medical Sciences, widely known as the "Pavlov Session," declared that the physiological theory of Pavlov should be the sole foundation of Soviet psychiatry. ${ }^{5,6,9,12}$ Protesters against Pavlovian psychiatry had to abandon their views in public or be dismissed from their positions. ${ }^{6,10,12}$ Based on the theory of conditioned reflex,
Pavlov hypothesized that every mental disease is caused by pathology involving "superior nervous activity."5,6 Pavlov concluded that neuroses are the pathologic response to sudden unexpected stimuli. ${ }^{6,13}$ Consistent with the Pavlovian tradition, pediatric psychiatric disorders were predominantly attributed to prenatal and perinatal brain injury. ${ }^{14}$ Before the 1940s, genetic predisposition was the main explanation for the cause of schizophrenia. However, after declaring psychiatric genetics as a bourgeois pseudoscience, USSR biological psychiatry was more narrowly defined than was biological psychiatry in Western countries. ${ }^{5}$

The Soviet legacy of limited biological approaches to mental disease had a long-term impact on psychiatry in Eastern countries. ${ }^{13}$ As the foundation for psychiatric training and research in East Germany was based on Pavlovian biological psychiatry, the non-materialistic psychoanalytic approach was abandoned. ${ }^{8}$ In Lithuania and Armenia, only biological explanations were allowed to explain the causes of mental illness because social problems could not exist in an ideal socialist society. ${ }^{14,15}$ In Czechoslovakia, biological psychiatry achieved academic hegemony. ${ }^{16}$

\section{Implications for North Korean psychiatry}

Psychiatry in North Korea seems to be affected by biologically-oriented socialist psychiatry. North Korean medical education and psychiatric practice has accepted the Pavlovian perspective (i.e., physiological disruption of nervous system activity) on the etiology of psychiatric disorders. Contrary to the neglect of genetics in Soviet psychiatry, North Korean doctors believe that schizophrenia and other psychotic disorders are closely related to the genetic constitution of individuals. As in the former USSR, however, the psychosocial and psychodynamic etiology of psychiatric disorders seems to be ignored in North Korea. Indeed, North Korean doctors have reported that the concept of the unconscious is not considered in discussions about psychiatric disorders in North Korean clinics. ${ }^{4}$ They reported that only familial or other personal problems, which are not directly related to the social system, were considered to be potential causes of neurasthenia in North Korean clinics. However, the attribution of psychiatric disorders to remnants of capitalism, which could be found in other socialist countries, ${ }^{7}$ was not reported by North Korean doctors.

\section{DIAGNOSES AND CLINICAL FEATURES OF PSYCHIATRIC DISORDERS}

\section{General}

The official statistics for psychiatric epidemiology in former socialist countries are usually corrupted and unreliable. ${ }^{17}$ As 
the prevalence of psychiatric disorders may be an indicator of the basic conditions of a society, psychiatric disorders should not exist in an ideal socialist society. During the Cultural Revolution, the presence of mental illness was denied in communist China because psychiatric disorders were thought to be by-products of a capitalistic system.?

\section{Schizophrenia}

A new category of schizophrenia, "sluggish schizophrenia," was created in the USSR. Sluggish schizophrenia was categorized under latent schizophrenia in the modified Soviet version of the ICD-9, and it was presumed to start with indiscernible symptoms and progress slowly with a devastating long-term prognosis. ${ }^{11,12}$ Soviet psychiatrists asked to be trained to uncover the hidden psychopathology of sluggish schizophrenia, which was thought to involve the thoughts or behaviors of political dissidents, called philosophical intoxication $^{5}$ or delusions of reformism. ${ }^{12}$ In China, overt opposition to the Communist Party was regarded as a persecutory or a political delusion associated with paranoid schizophrenia. ${ }^{7}$

Sluggish schizophrenia covers the spectrum of symptoms related to mood disorders, anxiety disorders, personality disorders, and somatization disorders. ${ }^{5}$ Additionally, as psychotic patients were considered a potential risk to the order and productivity of the socialist society, schizophrenia was over-diagnosed in the USSR. ${ }^{18}$ Indeed, Moscow was the city with the highest prevalence of schizophrenia in the world..$^{5,12,19,20}$ The prevalence of schizophrenia in Maoist China was equal to that in Western countries, whereas the prevalence of other psychiatric disorders was much lower. ${ }^{21}$

\section{Mood disorders and other neurotic disorders}

According to the Soviet version of the ICD-7, depression no longer existed and could only be recognized as a symptom of bipolar disorder, which was regarded as a biological disease. ${ }^{9}$ Even bipolar disorder was often diagnosed as schizophrenia. ${ }^{22}$ The prevalence of affective disorders was one-seventh of that of schizophrenia in China during the 1980s. ${ }^{22}$ According to nationwide epidemiologic studies in 1982 and 1993, the lifetime prevalence of affective disorders was less than $1 \%$ in China. ${ }^{23}$

During the Cultural Revolution in China, depression was considered an ideological problem that served as an excuse to withdraw from collective labor and mass mobilization. Patients with depression had to conceal their depressive symptoms, such as social withdrawal and loss of volition, which might be politically dangerous. ${ }^{24}$ The official lifetime prevalence of neurotic disorders in post-Mao China was less than $3 \%$, which was significantly lower than that in Taiwan. ${ }^{22}$

Given the social stigma attached to and the political hostili- ty directed at mental illness, Chinese patients had a greater tendency to somatize their depressive symptoms and to seek medical care rather than psychiatric treatment. ${ }^{21,25}$ Neurasthenia, the main symptoms of which are somatic in nature, might be a culturally and socially acceptable substitute for depression in China. Indeed, the majority of neurasthenia patients in China are responsive to anti-depressants. ${ }^{25}$ The emotional distress related to collective surveillance, repression of freedom of expression, and social discrimination against the underprivileged class in socialist society was usually expressed in a psychosomatic form in East Germany. ${ }^{8}$ In the Soviet disease classification system, somatoform disorders were included in the neurology section rather than the psychiatry section. ${ }^{9}$

During the post-socialist transition, depression increased rapidly in all socialist countries except East Germany. ${ }^{26}$ After the collapse of the communist dictatorship, depression became the most common psychiatric diagnosis in Romania, whereas depression had ranked only fourth in $1990 .{ }^{27}$ In Hungary, rapid changes in social and economic conditions led to an increase in depressive symptoms. ${ }^{28}$ The prevalence of mood disorders reached $9.1 \%$ in post-socialist Ukraine according to the World Health Organization (WHO) Mental Health Survey Consortium. ${ }^{29}$ It has been suggested that the increase in depression during the post-socialist transition was related to unemployment and economic inequality in the competitive job market or to the emergence of self-directed decision making, which was not possible under the repressive conditions of socialist societies. ${ }^{27,30}$ The tendency towards somatization might not disappear or may even be aggravated during the post-socialist transition. Mongolian people who had difficulty coping with social changes related to a fast-paced and competitive capitalist society complained of yadargaa, a culturebound syndrome manifested as fatigue and pain. ${ }^{31}$ Individuals channel mental distress into yadargaa in a society that strongly stigmatizes psychiatric disorders.

\section{Substance use disorders}

Alcoholism was considered to be a social and moral problem rather than a treatable disease in the USSR. Official statistics were distorted, and the psychiatry textbook argued that drug abuse and alcoholism were almost nonexistent in the ideal society of the USSR. ${ }^{5}$ However, despite strict regulations, alcohol-related disorders were not rare in the USSR. In the 1950s, $16.5 \%$ of psychiatric outpatient patients had alcoholrelated disorders. ${ }^{32}$ In the 1970s, one in seven psychiatric consultations in the USSR was related to alcoholism. High levels of consumption might continue even after a post-socialist transition. The prevalence of substance use disorders was reported to be $6.4 \%$ in post-socialist Ukraine. ${ }^{29}$ 


\section{Implications for North Korean psychiatry}

According to North Korean doctors' reports, the sphere of North Korean psychiatry has been confined primarily to schizophrenia and bipolar disorders. ${ }^{4}$ Most patients in psychiatric hospitals, the so-called "49th ward" in North Korea, are schizophrenic and a few are manic. Other neurotic disorders do not get much attention from North Korean society. Psychosis is generally believed to be more strongly associated with biological factors than are neurotic disorders. Thus, North Korean psychiatry seems to have been influenced by psychiatry in former socialist countries, where biological explanations for the etiology of mental illness were predominant. Furthermore, priority is given to more severe diseases in economically devastated North Korean society. Life-threatening medical problems, such as infectious diarrhea or tuberculosis, are more important than mental health issues. Among psychiatric disorders, more serious psychoses are likely the main concern of psychiatrists in North Korea.

North Koreans consider other neurotic disorders to be a result of the failure of individuals to exert willpower. North Korean doctors have reported that depressed patients are rarely treated in psychiatric hospitals. However, as depression and post-traumatic stress disorders are reportedly common in North Korean refugees, ${ }^{33-37}$ depression and anxiety disorders have probably been underdiagnosed in North Korea.

In North Korea, somatic symptoms of anxiety or depression have been included in the neurology or internal medicine section of the disease classification system. As in other socialist countries, mood or anxiety problems tend to be expressed as somatic symptoms, which are socially acceptable in North Korean society. These somatic symptoms are often diagnosed as "cardiac neurosis" (Shimjang Shingyungjeung) or "neurasthenia" (Shingyung Shoiyak), which are treated by general physicians or neurologists rather than psychiatrists. ${ }^{4} \mathrm{Ac}$ cording to North Korean medical understanding, neurasthenia starts with cardiac neurosis. Neurasthenia is understood to be caused by an imbalance of the autonomic nervous system, which can progress into a state of vegetative nervous dysfunction or "dysautonomia" (Jayulshingyung Shiljojeung), which is quite similar to clinical depression. Most neurasthenia patients present with somatic anxiety or insomnia as a chief complaint. They usually experience excessive dreaming or worry, nervousness, and loss of concentration at work. These symptoms are interpreted as signs of an abnormal physical status rather than as signs of psychological or psychosocial distress. Typically, physicians other than psychiatrists issue a medical certificate for neurasthenia, which sometimes can be used as an exemption from compulsory labor. ${ }^{4}$ However, some North Korean doctors reported that they knew from clinical experience that neurasthenia was common in housewives and officials who had to repress their emotions and believed that this condition was related to emotional problems. ${ }^{4}$

Although North Koreans in South Korea commonly display significant alcohol-related problems, ${ }^{38}$ alcohol-related disorders, with the exception of acute and vivid alcohol intoxication, are rarely diagnosed in North Korea. ${ }^{4}$ The under-diagnosis of alcohol dependence in North Korea is consistent with that in former socialist countries that officially report a low prevalence of such conditions. However, in real clinical situations, the diagnosis and treatment of alcohol dependence is uncommon in North Korea, ${ }^{4}$ whereas it was common in the USSR ${ }^{31}$ Plausible reasons for this include a shortage of alcoholic beverages, uncritical attitudes toward heavy alcohol consumption, or ignorance of alcohol-related disorders in North Korea.

\section{TREATMENT OF PSYCHIATRIC DISORDERS}

\section{Inpatient and outpatient treatment}

The Soviet mental health system relied primarily on inpatient treatment in large psychiatric hospitals, ${ }^{18}$ with the majority of psychiatric patients institutionalized and little community mental healthcare available. ${ }^{15,17,27,39}$ There were no financial incentives to discharge psychiatric patients because the amount of reimbursement was determined by the number of hospitalized patients. ${ }^{15,40}$ After being discharged from psychiatric hospitals, patients were followed up by psychiatrists who were in charge of their diagnosis, drug prescriptions, and in-person care. ${ }^{6,19}$ The mental health system in East Germany was also heavily concentrated in large outmoded psychiatric hospitals for chronic psychiatric patients. ${ }^{8}$ The relative paucity of trained psychiatrists in East Germany gave rise to the unequal distribution of the mental health workforce after reunification. ${ }^{41}$

Even during post-socialist transition periods, there was conflict between the new deinstitutionalization movement and the lack of social rehabilitation programs. Some Romanian patients with mild symptoms preferred to stay in psychiatric hospitals as long as possible to receive government welfare benefits. ${ }^{42}$ They were called "social cases" as they were admitted due to social need and not due to illness severity. ${ }^{42}$

\section{Biological therapy}

Psychiatric treatment in socialist societies was heavily dependent on pharmacological therapy. Psychopharmacological treatment remained the mainstay of psychiatric treatment even after the collapse of the communist bloc due to the routinized treatment patterns of psychiatrists and the reluctance 
of patients to pursue psychotherapy. Most of the healthcare budget for mental health was devoted to pharmacological treatment. ${ }^{17}$

Trends in antidepressant use differ by country. With China's open door policy in the post-Mao era, the prescription of antidepressants for former neurasthenia patients dramatically increased. ${ }^{24}$ However, due to ignorance about mental health problems among government officials, public subsidies for antidepressants were temporarily discontinued in Romania during the $1990 \mathrm{~s}^{27}$

Although pharmacological therapy was relatively free from ideological issues, it was strongly influenced by the economic status of each country. Some psychiatric patients had only limited access to inexpensive medication, ${ }^{16,18}$ and outdated therapies, such as an insulin coma therapy, was practiced in Czech psychiatric hospitals even after the post-socialist transition. ${ }^{16}$

\section{Psychological therapy}

Psychoanalysis was practiced by leading psychiatrists before the Stalin era. ${ }^{9}$ However, as mentioned earlier, the theory of psychoanalysis and the existence of the unconscious were denied by the Stalin government. ${ }^{5}$ In socialist countries, psychosocial explanations for psychiatric disorders were denied ${ }^{6}$ or confined to the effects of remnants of capitalism. ${ }^{7}$ Therefore, psychotherapy was usually not encouraged in Stalin's USSR, and there were few psychologists and psychotherapists in the early Soviet mental health system. In Czechoslovakia, practicing psychoanalysis became illegal under the communist regime ${ }^{16}$ Psychodynamic psychotherapy began to be practiced in former socialist countries that experienced the de-Stalinization movement only after the 1970s. ${ }^{14}$

However, special kinds of psychotherapy were allowed and offered to psychiatric patients in socialist countries. In some societies, education and training were believed to be helpful for treating mental health problems based on the conditioning theory of Pavlov. Occupational therapy was allowed as it was in line with the socialist ideology of labor. Group therapeutic education was conducted to treat mental illness believed to be caused by the remnants of the capitalist bourgeois worldview. ${ }^{7}$

\section{Implications for North Korean psychiatry}

Similar to other former socialist countries, North Korea is characterized by a predominance of in-patient rather than out-patient treatment. The North Korean healthcare delivery system for psychiatric disorders is composed of the 49th Prevention Center (49th ward) and the department of psychiatry in provincial hospitals. The 49th wards are located in areas that are geographically remote from social networks. If a pa- tient presents with psychotic symptoms, physicians are obliged to transfer the patient to the 49th ward with the approval of the vice president of the hospital. ${ }^{4}$

As in other former socialist countries, North Korea relies on biological therapy as the mainstay of psychiatry. However, psychopharmacological or other biological treatments in North Korea fell behind due to the social system and the devastated economy. Chlorpromazine or old typical antipsychotics are prescribed to psychotic patients in the 49th wards. North Korean doctors have reported that insulin coma therapy was performed until recently. ${ }^{4}$ Sedatives are also commonly prescribed by North Korean psychiatrists and parenteral administration of diazepam or barbiturate prescriptions are common for psychotic patients. ${ }^{4}$

In North Korea, pharmacotherapy for neurasthenia or cardiac neurosis is performed by physicians other than psychiatrists. Neurasthenia or cardiac neurosis, which involve symptoms similar to anxiety disorders or depression, are treated with benzodiazepines, oryzanol (rice brand oil) or camphor (cardiotonics) in North Korea. ${ }^{4}$ Additionally, herbal medicines also are used for neurasthenia or cardiac neurosis because of the shortage of drugs and the emphasis on Oriental medicine in North Korea. ${ }^{4}$ The widespread use of herbal medicine is a distinct characteristic of North Korean psychiatry that is slightly different from practices in other former socialist countries.

As was the case in earlier socialist countries, psychotherapy is not conducted in North Korea. Only subsistence farmingrelated occupational therapy is practiced in the 49th wards. However, some North Korean doctors in South Korea reported that they knew from their clinical experiences that their emotional support or reassurance could affect the prognosis of neurasthenia or cardiac neurosis. ${ }^{4}$

\section{SPECIAL MENTAL HEALTH ISSUES IN SOCIALIST SOCIETIES}

\section{Suicide}

Statistics regarding suicide in former socialist countries were not released until the 1990s, when many socialist countries began to report annual suicide data to WHO. Former socialist countries reportedly have a high suicide rate. ${ }^{43}$ In contrast to the low incidence of depression according to official statistics, the suicide rate in East Germany ranked third in the world in 1980s. ${ }^{8}$ Before unification, the suicide rate in East Germany was much higher than that in West Germany. ${ }^{42}$ The association between socialism and suicide may be due to political totalitarianism or the discouragement of religion. ${ }^{44}$

During the post-socialist transition, suicide rates rapidly increased in the former USSR and many Eastern European 
countries. ${ }^{27,45,46}$ The increase in suicide after the dramatic social and political changes in Eastern Europe has been interpreted as the result of social inequality or of the displacement of aggression from the society to the self..$^{45}$ The suicide rate in East Germany decreased and reached the level of the suicide rate in West Germany after reunification. ${ }^{43}$ This exception might be related to the lesser societal change in East Germany compared with other former socialist countries given the relatively favorable economic conditions or to the academic exchanges and exposure to West Germany before reunification as well as to the solidarity emerging from the shared experiences of East Germans. ${ }^{47}$

\section{Stigma}

As most psychiatric patients were psychotic and institutionalized in psychiatric hospitals, psychiatric patients in former socialist countries were likely to experience considerable social stigma. Psychiatric patients were regarded as socially inadequate. ${ }^{8}$ As some psychiatric conditions might represent the remnants of the despised capitalist system, the stigma might be aggravated. The social stigma of psychiatric disorders was deeply imprinted in public minds as the state-owned media spread the conflation between psychiatric patients and political dissidents. ${ }^{5}$ Additionally, the tendency to repress personal emotions or opinions in socialist society might have been related to reluctance to acknowledge psychiatric symptoms.

\section{Political abuse of psychiatry}

In the USSR, psychiatry was used for political reasons. Political dissidents in the USSR were hospitalized in psychiatric hospitals, where security agents could intervene with the diagnosis, treatment, and admission of patients. ${ }^{18}$ About onethird of political prisoners were hospitalized with physically disabled or mentally retarded patients. ${ }^{48}$ The World Psychiatry Association raised awareness of the political abuse of Soviet psychiatry, which resulted in decreased psychiatric admission of political dissidents. ${ }^{18,48}$ The political abuse of psychiatry also took place in Romania, Czechoslovakia, Hungary, Bulgaria, Cuba, and East Germany. ${ }^{8,20}$ The political abuse of psychiatry interfered with the development of rapport between patients and psychiatrists, ${ }^{8,12,17}$ which resulted in longterm complications. ${ }^{40}$

Psychiatric patients were regarded as having political or social problems in socialist countries. Patients with delusional disorders were sent to political prisons or labor concentration camps during the Cultural Revolution in China. ${ }^{49}$ The mental health system in East Germany was perverted to control "socially inadequate" people, such as alcoholics, prostitutes, and criminals. ${ }^{8}$

\section{Implications for North Korean psychiatry}

The suicide rate was not reportedly high in North Korea. North Korean doctors argue that suicide is taboo in North Korean society because suicide is a counterrevolutionary act against the Fatherland and may result in extermination of the whole family. ${ }^{4}$ However, the suicide rate increased during the post-socialist transition in many countries. Additionally, the current suicide rate in South Korea ranks the highest in the world. Therefore, it is possible that a dramatic increase in suicide in the former North Korea would occur after reunification.

As in other socialist countries, North Korea places a social stigma on psychiatric patients. In North Korea, psychiatric patients are assumed to behave bizarrely and stupidly and are sometimes labeled "49th" after the name of psychiatric hospitals. North Koreans have widespread doubts about the efficacy of psychiatric treatment. There are virtually no references to psychiatric disorders or suicide in the North Korean media because psychiatric disorders should not exist in an ideal socialist society. The presence of mental illness would be regarded as socially undesirable even by the government. Psychiatric patients are admitted to hospitals in geographically remote areas. The isolation of psychiatric patients from the social network might be related to the protection of the ideal society from potentially socially undesirable persons.

Unlike the situation in former socialist countries, there is no evidence that psychiatry is abused to punish political dissidents in North Korea although political issues are emphasized in the North Korean medical education curriculum..$^{50}$ This may be due to the presence of other sorts of concentration camps for political dissidents or to the confinement of psychiatry to brain-related biological disorders that are distant from political issues.

\section{CONCLUSIONS}

North Korean psychiatry is heavily influenced by the traditional psychiatry of former socialist countries. Psychiatric disorders are understood to be caused mainly by biological factors rather than by psychosocial or psychodynamic factors. Psychiatry covers only a limited sphere of psychotic disorders. Neurotic disorders are ignored or are regarded as neurological or physical problems by psychiatry. Psychiatric treatment depends primarily on outdated biological therapies and longterm admissions to psychiatric hospitals, and psychiatric patients seem to experience enduring stigmatization. However, unlike the situation in former socialist countries, there is no evidence of the political abuse of psychiatry in North Korea.

North Korea is characterized by the dynamic coexistence of characteristics common to both socialist societies and those 
that have undergone a post-socialist transition. Given the mental health crises that have afflicted transitional societies, it seems likely that a unified Korea would face enormous mental health challenges. Thus, we need to prepare for a potential reorganization of the entire mental health system, including education, diagnosis, and treatment, in a unified Korea.

\section{Acknowledgments}

This work was supported by the National Research Foundation of Korea (NRF) grant funded by the Korea government (MEST) (2013R1A1A2A 10007021) and the fund from the Institute for Peace and Unification Studies, Seoul National University (2012).

\section{REFERENCES}

1. Lee YM, Shin OJ, Lim MH. The psychological problems of North Korean adolescent refugees living in South Korea. Psychiatry Investig 2012;9:217-222.

2. Yu SE, Eom JS, Jeon WT. The factors affecting the development of national identity as South Korean in North Korean refugees living in South Korea. Psychiatry Investig 2012;9:209-216.

3. Kim HH, Lee YJ, Kim HK, Kim JE, Kim SJ, Bae SM, et al. Prevalence and correlates of psychiatric symptoms in North Korean defectors. Psychiatry Investig 2011;8:179-185.

4. Kim SJ, Park YS, Lee HW, Park SM. Current situation of psychiatry in North Korea: From the viewpoint of North Korean medical doctors. Kor J Psychosom 2012;20:32-39.

5. Korolenko CP, Kensin DV. Reflections on the past and present state of Russian psychiatry. Anthropol Med 2002;9:51-64.

6. Zajicek B. Scientific Psychiatry in Stalin's Soviet Union: The Politics of Modern Medicine and the Struggle to Define "Pavlovian" Psychiatry, 1939-1953 [PhD Thesis] . Chicago, IL: Department of History, University of Chicago; 2009.

7. Munro RJ. Political psychiatry in post-Mao China and its origin in the Cultural Revolution. J Am Acad Psychiatry Law 2002;30:97-106.

8. Eghigian G. Was there a Communist Psychiatry? Politics and East German psychiatric care 1945-1989. Harv Rev Psychiatry 2002;10:364-368.

9. Miller MA. The theory and practice of psychiatry in the Soviet Union. Psychiatry 1985;48:13-24.

10. Angelini A. History of the unconscious in Soviet Russia: From its origins to the fall of the Soviet Union. Int J Psychoanal 2008;89:369-388.

11. Bloch S. Psychiatry as ideology in the USSR. J Med Ethics 1978;4:126131.

12. Lavretsky H. The Russian concept of schizophrenia: A review of the literature. Schizophr Bull 1998;24:537-557.

13. Skultans V. From damaged nerves to masked depression: inevitability and hope in Latvian psychiatric narratives. Soc Sci Med 2003;56:24212431.

14. Puras D. Treatment approaches in Lithuanian child psychiatry: Changing the attitudes. Nord J Psychiatry 1994;48:397-400.

15. Soghoyan A, Gasparyan K. Brief review of situation of social psychiatry in Armenia. Ann Gen Psychiatry 2010;9(Suppl 1):S236.

16. Kerr A, Peck E. Psychiatry in Prague: Some personal impressions. Psychiatr Bull 1991;15:4-6.

17. Tomov T. Mental health reforms in Eastern Europe. Acta Psychiatr Scand Suppl 2001;(410):21-26.

18. Ougrin D, Gluzman S, Dratcu L. Psychiatry in post-communist Ukraine: dismantling the past, paving the way for the future. Psychiatr Bull 2006; 30:456-459.

19. Wing JK. Psychiatry in the Soviet Union. Br Med J 1974;1:433-436.

20. van Voren R. Political abuse of psychiatry-- an historical overview. Schizophr Bull 2010;36:33-35.

21. Lin KM, Kleinman A. Recent development of psychiatric epidemiology in China. Cult Med Psychiatry 1981;5:135-143.

22. Cheung P. Adult Psychiatric epidemiology in China in the 80s. Cult Med Psychiatry 1991;15:479-496.

23. Lee S, Tsang A, Huang YQ, He YL, Liu ZR, Zhang MY, et al. The epidemiology of depression in metropolitan China. Psychol Med 2009;39: 735-747.

24. Lee S. Diagnosis postponed: shenjing shuairuo and the transformation of psychiatry in post-Mao China. Cult Med Psychiatry 1999;23:349380.

25. Kleinman A. Neurasthenia and depression: a study of somatization and culture in China. Cult Med Psychiatry 1982;6:117-190.

26. Bramesfeld A, Grobe T, Schwartz F. Prevalence of depression diagnosis and prescription of antidepressants in East and West Germany: an analysis of health insurance data. Soc Psychiatry Psychiat Epidemiol 2010;45:329-335.

27. Lonescu C. Depression in post-communist Romania. Lancet 2005;365: 645-646.

28. Kopp M, Skrabski A, Szedmák S. Psychosocial risk factors, inequality and self-rated morbidity in a changing society. Soc Sci Med 2000;51: 1351-1361.

29. Demyttenaere K, Bruffaerts R, Posada-Villa J, Gasquet I, Kovess V, Lepine JP, et al. Prevalence, severity, and unmet need for treatment of mental disorders in the WHO World Mental Health Surveys. JAMA 2004; 291:2581-2590.

30. Neumann J. Psychiatry in eastern europe today: mental health status, policies, and practices. Am J Psychiatry 1991;148:1386-1389.

31. Kohrt BA, Hruschka DJ, Kohrt HE, Panebianco NL, Tsagaankhuu G. Distribution of distress in post-socialist Mongolia: A cultural epidemiology of yadargaa. Soc Sci Med 2004;58:471-485.

32. Wortis J. Alcoholism in the Soviet Union: Public health and social aspects. Am J Public Health Nations Health 1963;53:1644-1655.

33. Lee Y, Lee MK, Chun KH, Lee YK, Yoon SJ. Trauma experience of North Korean refugees in China. Am J Prev Med 2001;20:225-229.

34. Jeon W, Hong C, Lee C, Kim DK, Han M, Min S. Correlation between traumatic events and posttraumatic stress disorder among North Koreans in South Korea. J Traumatic Stress 2005;18:147-154.

35. Han IY. Depressive traits of North Korean defectors. Korean J Fam Soc Work 2001;11:78-94.

36. Eom TW, Lee KY. The relationship among social problem-solving capability, social support and depression of North Korean defectors. Korean J Fam Soc Work 2004;18:5-32.

37. Kim HK, Oh SS. The MMPI- 2 profile of North Korean female refugees. Korean J Psychology 2010;29:1-20.

38. Jeon WT, Yu SE, Cho YA, Eom JS. Traumatic experiences and mental health of North Korean refugees in South Korea. Psychiatry Investig 2008;5:213-220

39. Tosevski DL, Christodoulou GN, Kontaxakis V, Christodoulou N. Provision of psychiatric services and mental health reform in Eastern Europe and the Balkans. Eur Psychiat Rev 2008;1:9-11.

40. Jenkins R, Klein J, Parker C. Mental health in post-communist countries. BMJ 2005;331:173-174.

41. Bauer M. Psychiatry in former East and West Germany since reunification. Psychiatr Bull 1994;18:637-639.

42. Friedman JR. The "social cases": Illness, psychiatry, and deinstitutionalization in postsocialist Romania. Med Anthropol Q 2009;23:375-396.

43. Schmidtke A, Weinacker B, Stack S, Lester D. The impact of the reunification of Germany on the suicide rate. Arch Suicide Res 1999;5:233239.

44. Lester D. Why People Kill Themselves. Springfield, IL: Charles Thomas; 1992.

45. Lester D. Suicide and homicide after the fall of communist regimes. Eur Psychiatry 1998;13:98-100.

46. Mäkinen IH. Eastern European transition and suicide mortality. Soc Sci Med 2000;51:1405-1420.

47. Achberger M, Linden M, Benkert O. Psychological distress and psychi- 
atric disorders in primary health care patients in East and West Germany 1 year after the fall of the Berlin Wall. Soc Psychiatry Psychiatr Epidemiol 1999;34:195-201.

48. van Voren R. Comparing Soviet and Chinese political psychiatry. J Am Acad Psychiatry Law 2002;30:131-135.
49. Appelbaum PS. Law \& Psychiatry: Abuses of law and psychiatry in China. Psychiatr Serv 2001;52:1297-1298.

50. Park YJ, Park HW. A study of the medical educational system in North Korea. Uisahak 1998;7:63-76. 